\title{
Escherichia coli ColV plasmid pRK100: genetic organization, stability and conjugal transfer
}

\author{
Jerneja Ambrožič, Alenka Ostroveršnik,† Marjanca Starčič, Irena Kuhar, \\ Miklavž Grabnar and Darja Žgur-Bertok
}

Author for correspondence: Darja Žgur-Bertok. Tel: +386 6112333 88. Fax: +38661273390. e-mail: Darja.Zgur@uni-Lj.Si

Department of Biology, Biotechnical Faculty, University of Ljubljana, Večna pot 111,1000

Ljubljana, Slovenia

\begin{abstract}
Uropathogenic Escherichia coli strains express chromosomal and plasmidencoded virulence-associated factors such as specific adhesins, toxins and ironuptake systems. A ColV plasmid (pRK100) of a uropathogenic strain and its host KS533 were studied. The host strain encodes the K1 capsule, and P and S fimbriae, but neither haemolysin nor the cytotoxic-necrotic factor CNF1, indicating that this strain does not harbour a larger pathogenicity island. A restriction map of pRK100 was constructed on the basis of hybridization experiments and nucleotide sequencing. PRK100 harbours Colv, the conserved replication region RepFIB, the aerobactin-uptake system, a RepFIC replicon and additionally Colla as well as transposon Tn5431. The location of the RepFIC replicon was similar to that in plasmid F. ColV plasmids and $F$ thus share a region spanning more than half the length of plasmid $F$. Even though their replication and transfer regions are homologous, ColV plasmids are found only in $E$. coli strains. Among the four other species tested, conjugal transfer of pRK100 was demonstrated, with low frequency, only to Klebsiella pneumoniae, suggesting that a natural barrier effectively bars transfer. In vitro stability of the plasmid with integration into the chromosome to ensure maintenance in the presence of an incompatible plasmid was demonstrated.
\end{abstract}

Keywords: ColV plasmid, plasmid pRK100, stability, conjugal transfer

\section{INTRODUCTION}

Pathogenic strains of Escherichia coli can cause intestinal and extraintestinal infections as well as newborn meningitis (Ørskov \& Ørskov, 1992). They encode various virulence determinants - adhesins, toxins, capsules, invasins and other virulence factors - on the chromosome, on plasmids, or on the genomes of bacteriophages. Virulence genes can be organized into large chromosomal blocks termed pathogenicity islands (Blum et al., 1995).

Plasmids are self-replicating and are normally not essential for bacterial growth; however, they often encode antibiotic resistances, colicins and various virulence determinants. Conjugative plasmids, in particular, facilitate the exchange and spread of resistances to antibiotics and chemicals, virulence factors and metabolic properties. The ColV plasmids form a heterogeneous group of large plasmids belonging to the IncFI

†Present address: Krka Pharmaceutical Company, Novo mesto, Slovenia. incompatibility group and encoding the production of colicin V (Waters \& Crosa, 1991). ColV plasmids are harboured primarily by virulent enteric bacteria and encode several virulence-associated properties. Colicin V is a small molecule, but is not SOS inducible and is therefore actually a microcin (Braun et al., 1994). Recent studies in a chicken embryo model system have shown that an avirulent wild-type avian $E$. coli strain transformed with the cloned colicin $\mathrm{V}$ genes became virulent, demonstrating that colicin $\mathrm{V}$ has a direct role in virulence enhancement (Wooley et al., 1994). Most colicin V plasmids also encode the aerobactin-uptake system and increased serum survival as well as resistance to phagocytosis. They could serve as models for the study of the evolution and molecular biology of other virulence plasmids.

ColV plasmids can harbour more than one replicon. The main replicon is homologous to the RepFIB of plasmid $F$. This replication region, along with the aerobactinuptake system, is highly conserved. Some ColV plasmids also carry a replicon homologous to RepFIA of plasmid $F$ and it has been reported that pColV-K30, the 
prototypic ColV plasmid, also carries an incomplete RepFIC (Waters \& Crosa, 1991) even though its location has not been determined.

Colicin V production was first described more than 70 years ago (Gratia, 1925), indicating that ColV plasmids were present in natural E. coli populations well before the widespread use of antibiotics. Use of antibiotics has probably selected for carriage of additional virulence and resistance determinants on ColV plasmids.

pRK100 is an approximately $145 \mathrm{~kb}$ conjugative plasmid which was discovered in a uropathogenic $E$. coli strain (Žgur-Bertok \& Grabnar, 1990). The plasmid encodes colicins V and Ia, the aerobactin-uptake system and the $16.1 \mathrm{~kb}$ transposon $\operatorname{Tn} 5431$ with ampicillin and tetracycline resistance determinants (Žgur-Bertok et al., 1994, 1996). The present work was carried out to study pRK100, to prepare its map, and to gain insight into its evolution, conjugational transfer and stability.

\section{METHODS}

Bacterial strains, plasmids and media. The E. coli strains and plasmids used in this study are listed in Table 1. KS533 is a uropathogenic strain, serotype rough : $\mathrm{K} 1 \mathrm{H} 7$ (determined by I. Ørskov), isolated at the Institute of Microbiology, Medical Faculty of Ljubljana. It harbours a large $(145 \mathrm{~kb})$ conjugative plasmid, pRK100 (Žgur-Bertok \& Grabnar, 1990). E. coli HB101 was used as the recipient strain for the conjugative transfer of plasmids pRK100 and RSF2001, a kanamycinresistant derivative of plasmid F. E. coli $\mathrm{DH} 5 \alpha$ was used as recipient for recombinant plasmids.

Plasmid pColVK-30, whose map has already been published (Waters et al., 1989), was used for comparison of probe binding in the hybridization experiments for IS1, RepFIA, RepFIB, RepFIC, the aerobactin-uptake system and the tra region. Plasmids of the Couturier bank of rep probes were used for replicon typing.

The Klebsiella pneumoniae, Enterobacter cloacae and Pseudomonas aeruginosa strains used as recipients in conjugation experiments are clinical isolates. The Salmonella typhimurium recipient was LT2.

Strains were grown in Luria-Bertani (LB) medium. When necessary, $\mathrm{LB}$ was supplemented with: $10 \mu \mathrm{g}$ ampicillin $\mathrm{ml}^{-1}$ (Ap); $10 \mu \mathrm{g}$ tetracycline $\mathrm{ml}^{-1}(\mathrm{Tc}) ; 100 \mu \mathrm{g}$ streptomycin $\mathrm{ml}^{-1}$ $(\mathrm{Sm}) ; 10 \mu \mathrm{g}$ chloramphenicol $\mathrm{ml}^{-1}(\mathrm{Cm}) ; 30 \mu \mathrm{g}$ kanamycin $\mathrm{ml}^{-1}(\mathrm{Kn})$. For selection of $S$. typhimurium, K. pneumoniae, Ent. cloacae, $P$. aeruginosa tranconjugants, Simmons citrate media (Collee \& Miles, 1989) supplemented with the appropriate antibiotics was used.

General DNA manipulation techniques. Prior to DNA manipulation, plasmids pRK100 and pColVK-30 were transferred to E. coli HB101. Isolation of plasmid and chromosomal DNA, large-scale isolation of CsCl-purified pRK100, and ligation and transformation experiments were performed as described by Sambrook et al. (1989). To visualize shorter restriction fragments pRK100 DNA was concentrated by ultrafiltration through a Centricon concentrator (Amicon) prior to restriction enzyme cleavage. Plasmids pRK100 and pColVK-30 were cleaved with EcoRI, HindIII, SalI, XhoI and by double cleavages. Plasmids carrying cloned inserts of pRK100 were additionally cleaved with AccI, BamHI, ClaI,
DraI, PstI and PvuII. Restriction endonuclease digestions were carried out according to the instructions of the supplier. DNA fragments were purified from agarose gels using the Geneclean II system (Bio101).

Agarose gel electrophoresis and restriction fragment size determination. Restriction enzyme digests of pRK100 were separated by constant field (CFGE) and pulsed-field (PFGE) gel electrophoresis. For separation and size determination of restriction fragments ranging from 0.2 to $7 \mathrm{~kb}$, CFGE with $0.5-2 \%$ submarine agarose gels was used. Larger fragments were separated by PFGE (Pharmacia Biotech, Gene Navigator System).

DNA hybridization for pRK100-encoded determinants. DNA labelling and hybridization experiments were carried out using the DIG DNA labelling and detection kit (Boehringer). Hybridization experiments were performed to detect the aerobactin-uptake system, ColV, the tra operon, replicons first to determine which replication regions were present and subsequently their position (RepFIB, RepFIC, Rep9) - IS1 sequences and chromosomal $\mathrm{P}$, type $\mathrm{I}$ and $\mathrm{S}$-fimbriae. The following labelled probes were used. For the aerobactinuptake system the $2.7 \mathrm{~kb}$ Sall-BamHI fragment of pABN1 (De Lorenzo et al., 1986) with genes iucA and iucB was used, and for ColV the $0.5 \mathrm{~kb} P v u \mathrm{II}-B g l \mathrm{II}$ fragment of $\mathrm{pHK} 11$ with $c v a \mathrm{C}$ and the overlapping cvi genes (Gilson et al., 1987). All EcoRI restriction fragments of pRK100 were labelled and used to probe the Couturier bank of rep plasmids (Couturier et al., 1988): for RepFIB the $1.2 \mathrm{~kb}$ PstI fragment of pUBL2404; for RepFIC the $0.9 \mathrm{~kb}$ EcoRI-HindIII fragment of pUBL2440; for Rep9 the $0.5 \mathrm{~kb}$ Pst I fragment of pUBL2422 (Couturier et al., 1988). For the tra operon, EcoRI fragments of pED100 and the $8.3 \mathrm{~kb}$ EcoRI restriction fragment $\mathrm{f} 6$ of pED100 (Willets \& Johnson, 1981) were used, and for detection of IS1 the $2.9 \mathrm{~kb}$ PvuII fragment of pTC72\#24 (kindly provided by M. Chandler).

The $0.9 \mathrm{~kb}$ EcoRI-HindIII fragment of pFDH1 and the three longest $(27,20$ and $17 \mathrm{~kb})$ EcoRI fragments of pRK100 were also individually labelled and used to probe EcoRI, HindIII, Sall, XhoI and double digestions of pRK100.

Stringent conditions were used for all hybridization experiments described in this report.

Colicin production. ColV and Colla production was determined using the overlay method (Pugsley, 1985) with indicator strains of the Pugsley collection of colicinogenic strains and with strains KH1038 (sensitive only to ColV), KH1044 (resistant to ColV) and AB1133 (sensitive to all colicins).

Resistance to the bactericidal action of serum. E. coli C600 and $\mathrm{C} 600$ (pRK100), as well as E. coli KS533 with and without pRK100, were tested for serum survival or resistance. Serum survival was tested in the presence of $1 \%, 2 \%$ and $3 \%$ human serum (Moll et al., 1980).

Plasmid stability and curing. Plasmid stability was studied by inoculation of the strain into LB medium without antibiotics and incubating at $37^{\circ} \mathrm{C}$ with shaking. The next day the cell suspension was diluted into fresh LB medium and again incubated at $37^{\circ} \mathrm{C}$. After 21 passages the cell suspension was diluted and plated. Colonies were then transferred to grids and tested for antibiotic resistances and colicin production.

Plasmid stability was further tested by introducing pED100, a conjugative derivative of plasmid $\mathrm{F}$ also of the IncF1 incompatibility group, into KS533. 
Table 1. E. coli strains and plasmids

\begin{tabular}{|c|c|c|}
\hline $\begin{array}{l}\text { Strain or } \\
\text { plasmid }\end{array}$ & Relevant properties & Source or reference* \\
\hline \multicolumn{3}{|l|}{ Strains } \\
\hline KS533 & Rough: $\mathrm{K} 1: \mathrm{H} 7$ harbouring $\mathrm{pRK} 100$ & Žgur-Bertok et al. (1990) \\
\hline HB101 & hsdR hsdM recA13 supE44 leuB6 lacZ proA2 & D. Ehrlich ${ }^{1}$ \\
\hline DH5 $\alpha$ & thi-1 recA bsdR17 lac & A. Francky ${ }^{2}$ \\
\hline $\mathrm{C} 600$ & thi-1 thr-1 leuB6 lacY1 $\mathrm{Sm}^{\mathrm{R}}$ & B. Bachmann ${ }^{3}$ \\
\hline AB1133 & Sensitive to all colicins & B. Bachmann \\
\hline KH1038 & Sensitive only to ColV & K. G. Hardy ${ }^{4}$ \\
\hline KH1044 & Resistant to ColV & K. G. Hardy \\
\hline \multicolumn{3}{|l|}{ Plasmids } \\
\hline pRK100 & ColV plasmid with $\operatorname{Tn} 5431$ & Žgur-Bertok et al. (1990) \\
\hline pColV-K30 & Colv & Lehrbach \& Broda (1984) \\
\hline RSF2001 & F plasmid with $\mathrm{Kn}^{\mathrm{R}}$ & Heffron et al. (1977) \\
\hline pUC19 & $\mathrm{Ap}^{\mathrm{R}}$ & Yanisch-Perron et al. (1985) \\
\hline pAlter & $\mathrm{Tc}^{\mathrm{R}}$ & Promega \\
\hline pTC72\#24 & IS1 & M. Chandler ${ }^{5}$ \\
\hline pABN1 1 & Aerobactin-uptake system & De Lorenzo et al. (1986) \\
\hline pHK11 & Colicin V & Gilson et al. (1987) \\
\hline pED100 & tra operon & Willets \& Johnson (1981) \\
\hline pPKL4 & Fimbriae type I & Ott et al. (1991) \\
\hline pRHU845 & pap/prs & Ott et al. (1991) \\
\hline pANN801-13 & $s f a / f o c$ & Ott et al. (1991) \\
\hline pUBK2404 & RepFIB & Couturier et al. (1988) \\
\hline pUBL2440 & RepFIC & Couturier et al. (1988) \\
\hline pUBL2422 & Rep9 & Couturier et al. (1988) \\
\hline pFDH1 & pAlter with the $20 \mathrm{~kb}$ HindIII fragment of pRK100 & This study \\
\hline $\mathrm{pFDH} 2$ & pAlter with the 20 and $12 \mathrm{~kb}$ HindIII fragments of pRK100 & This study \\
\hline pFDS1 & pAlter with the $17.5 \mathrm{~kb}$ Sall fragment of pRK100 & This study \\
\hline pUX1 & pUC19 with $0.9 \mathrm{~kb}$ EcoRI/HindIII of pFDH1 & This study \\
\hline pUV55 & pUC19 with the $5 \mathrm{~kb}$ EcoRI fragment of pFDH2 & This study \\
\hline pUX5 & pUC19 with the $3.6 \mathrm{~kb}$ EcoRI fragment of pFDH1 & This study \\
\hline pUX600 & pUC19 with $0.6 \mathrm{~kb}$ PstI fragment of pUX5 & This study \\
\hline
\end{tabular}

* 1, Laboratoire Génétique Microbienne, INRA, Domain de Vilvert, Jouy en Josas, France; 2, The Boris Kidric Institute of Chemistry, Ljubljana, Slovenia; 3, E. coli Genetic Stock Center, Department of Biology, Yale University, New Haven, CT, USA; 4, Biogen SA, Geneva, Switzerland; 5, Centre de Recherche de Biochimie et Génétique Cellulaire du CNRS, Toulouse, France.

Plasmid curing was also performed with acridine orange and SDS treatment (Hardy, 1987).

Conjugational transfer experiments. For conjugational transfer of plasmids the donor and recipient strains were overstreaked on an LB plate and incubated overnight at $37^{\circ} \mathrm{C}$. Following the mating period, a portion of the mating mixture was removed from the growth surface with a sterile rod and was streaked on a selection plate. For liquid mating, overnight cultures of donor and recipient strains were diluted 50 -fold in LB liquid medium. The donor strain was incubated at $37^{\circ} \mathrm{C}$ for $3 \mathrm{~h}$ without shaking and the recipient strain for $2 \mathrm{~h}$ with shaking. A mating mixture consisting of $0.5 \mathrm{ml}$ of the donor and $4.5 \mathrm{ml}$ of the recipient cultures was prepared and incubated for $20 \mathrm{~h}$ at $37^{\circ} \mathrm{C}$. Transconjugants were selected on Simmons citrate agar plates, supplemented with Tc and Ap when testing for transfer of pRK100 and with Kn when testing for transfer of plasmid RSF2001. E. coli transconjugants were selected on LB media supplemented with Sm, Ap and Tc for transfer of pRK100 or Sm and Kn for transfer of RSF2001. Negative controls were prepared by plating donor and recipient strains separately on selective media. Transconjugants were screened for plasmid DNA.

Production of type I fimbriae, P fimbriae, 5 fimbriae, CNF1 and haemolysin. Cleaved KS533 chromosomal DNA was probed for type I fimbriae with the labelled $6 \mathrm{~kb}$ Pst I fragment of pPKL4, for pap/prs with the $4 \mathrm{~kb}$ HindIII-EcoRI fragment of pRHU845 and for $s f a / f o c$ with the $6 \mathrm{~kb}$ Clal-EcoRV fragment of pANN801-13. PCR was carried out with primers specific for the cytotoxic necrotizing factor CNF1: CNF1 primer 1 (CTGACTTGCCGTGGTTTAGTCGG) and CNF1 primer 2 (TACACTATTGACATGCTGCCCGGA). PCR was carried out in the following steps: heating at $94^{\circ} \mathrm{C}$ for $2 \mathrm{~min}$, followed by 30 cycles of denaturation at $94^{\circ} \mathrm{C}$ for $1 \mathrm{~min}$, annealing at $59^{\circ} \mathrm{C}$ for $1.5 \mathrm{~min}$, extension at $72^{\circ} \mathrm{C}$ for $2 \mathrm{~min}$, and the final extension for $5 \mathrm{~min}$ at $72{ }^{\circ} \mathrm{C}$.

Haemolysin production was tested by plating onto LB plates containing $2 \%$ washed sheep erythrocytes.

DNA sequencing. Single- and double-stranded sequencing of cloned pRK100 restriction fragments was performed using the 
Sequenase version 2.0 Sequencing Kit (USB) and the Silver sequencing kit (Promega). Primers were the commercially available M13/pUC forward and reverse sequencing primers.

\section{RESULTS}

\section{Location of Tn5431 and flanking regions}

Previously, we determined that pRK100 carries transposon Tn5431, encoding resistances to $\mathrm{Tc}$ and $\mathrm{Ap}$ (Zgur-Bertok et al., 1994). To determine the position of Tn5431 on pRK100, three clones carrying the antibiotic resistances of Tn5431, pFDH1, pFDH2 and pFDS1, were isolated (Fig. 1). pFDH1 harbours the $20 \mathrm{~kb}$ HindIII fragment, pFDH2 two consecutive HindIII fragments, $20 \mathrm{~kb}$ and $12 \mathrm{~kb}$ long (isolated by cloning partially HindIII-digested pRK100 DNA), while pFDS1 carries the $17.5 \mathrm{~kb}$ SalI fragment. Using restriction mapping, hybridization experiments, and testing with indicator strains for colicin activity it was determined that pFDH1 and pFDS1 harbour an incomplete Tn5431 and that each plasmid carries one flanking region. pFDH1 carries ColIa, pFDS1 carries ColV, and pFDH2 carries the entire Tn5431, ColV and ColIa.

To confirm the hybridization and colicin typing results, plasmids pUV55 and pUX5, with $5 \mathrm{~kb}$ and $3.6 \mathrm{~kb}$ EcoRI fragments of $\mathrm{pFDH} 2$, respectively were prepared (Figs 1 and 2). Subsequently, the $0.6 \mathrm{~kb}$ PstI restriction fragment of pUX5 was subcloned to generate pUX600. Singlestranded sequencing of the pUV55 insert with the reverse sequencing primer and of the pUX5 insert with the forward sequencing primer showed that $\operatorname{Tn} 5431$ was inserted into Colla at nucleotide position 3424 (determined by alignment with the sequence deposited under EMBL accession number M13819) of the con-

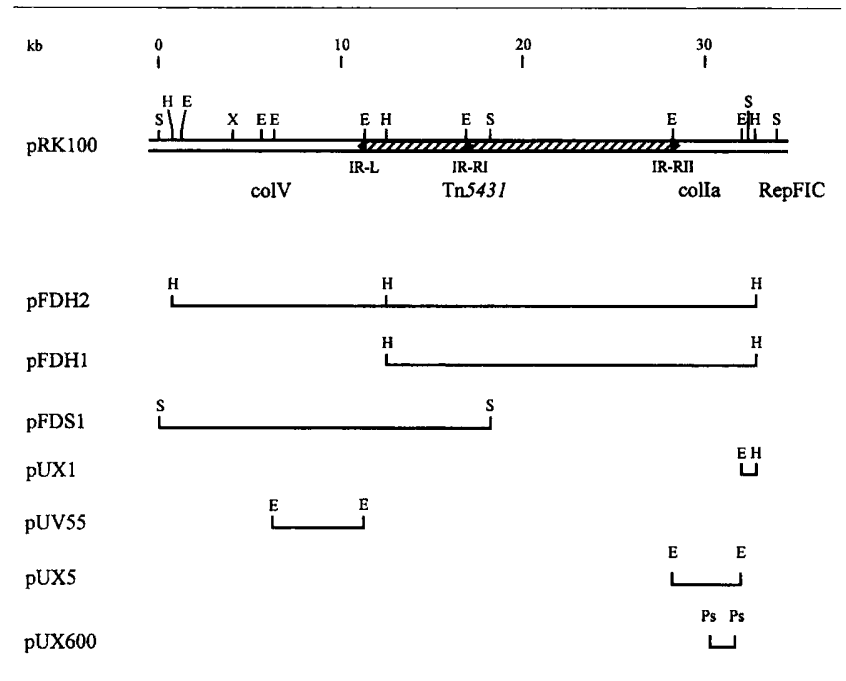

Fig. 1. Schematic representation of the pRK100 region encoding ColV, Tn5431, Colla, RepFIC and the restriction enzyme maps of clones harbouring restriction fragments of this region. Restriction sites: E, EcoRI; H, HindIII; Ps, Pstl; S, Sall; X, Xhol. Pstl restriction sites are shown only for pUX600. The hatched area denotes $\mathrm{Tn} 5431$, with the arrowheads designating inverted repeats (IR).
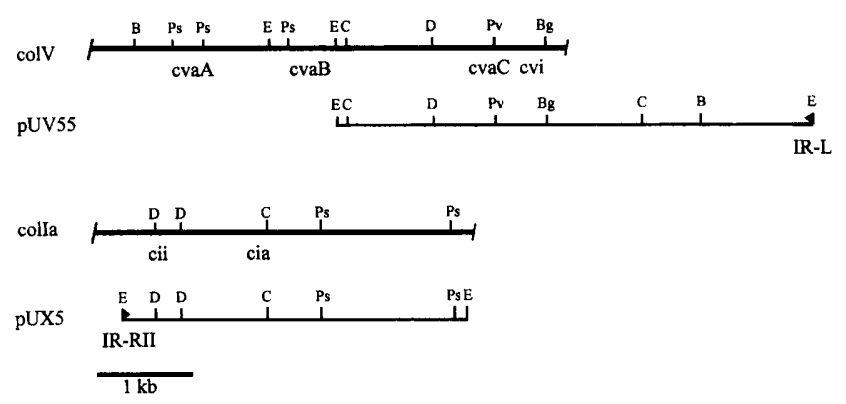

Fig. 2. Top: comparison of the restriction map of ColV, prepared on the basis of sequences deposited under accession numbers X57525 and X57524 and denoted with a heavy line, with the pUV55 restriction map. The shaded line at the righthand end of the pUV55 map denotes the conserved sequences in the direct vicinity of the Colla immunity gene from nucleotide positions 3425-3727. The arrowhead denotes the left inverted repeat (IR-L) of Tn5431. Bottom: comparison of the restriction map of Colla, prepared on the basis of the deposited sequence and denoted with a heavy line, with the restriction map of pUX5. The arrowhead denotes the right inverted repeat (IR-RII) of Tn5431. Restriction sites: B, BamHI; Bg, Bglli; C, Clal; D, Dral; Pv, Pvull.

served ORF2, which is not involved in Colla production. Upstream of the IR-L of Tn5431 are sequences from nucleotide positions 3425 to 3727 of the $3727 \mathrm{bp}$ deposited sequence. Downstream of the Tn5431 IR-RII are the colicin Ia immunity and structural genes. Singlestranded sequencing of the $0.6 \mathrm{~kb} P s t \mathrm{I}$ insert of pUX600 with the forward and reverse sequencing primers demonstrated conservation of sequences of the Colla structural gene, while the ORFI sequences are not conserved. Alignment of the nucleotide sequence obtained by single-stranded sequencing of pUV55 DNA with the forward primer and the Colv sequence deposited under EMBL accession number X57525 showed conservation of nucleotide sequences of the colicin $\mathrm{V} c v a \mathrm{C}$ structural gene and the $c v i$ immunity gene. Nucleotide sequencing also showed characteristic $5 \mathrm{bp}$ repeats of target DNA at both Tn5431 ends, confirming that transposition had occurred.

Altogether these results demonstrated that Tn5431 had transposed into a region encoding Colla and ColV. Tn5431 is flanked on one side by ColV and on the other by ColIa.

\section{Replication regions, aerobactin system and IS1}

Waters \& Crosa (1986) reported conservation of the replication region RepFIB among all ColV plasmids investigated and, further, that most encode the aerobactin iron-uptake system with an upstream and downstream insertion sequence IS1. To detect and map these nucleotide sequences we performed hybridizations of specific labelled probes with restriction enzyme digests of pRK100 and, for comparison, with fragments of the prototypic plasmid pColV-K30.

Comparison of the hybridization signals demonstrated 


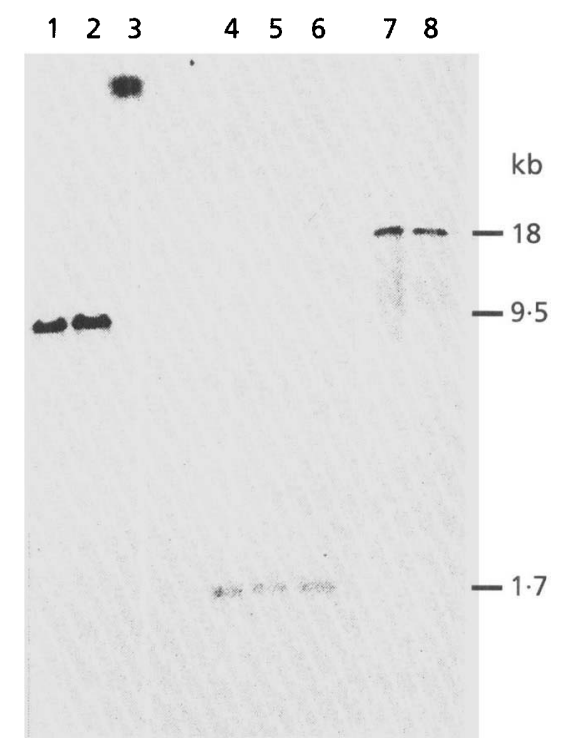

Fig. 3. Southern blot hybridization, with the RepFIB-specific probe, of pRK100 digested with: lane 1, EcoRI; lane 2, Xhol/EcoRl; lane 3, Xhol; lane 4, Hindlll; lane 5, Xhol/Hindlll; lane 6, EcoRI/HindIII; lane 7, Sall; lane 8, Xhol/Sall.

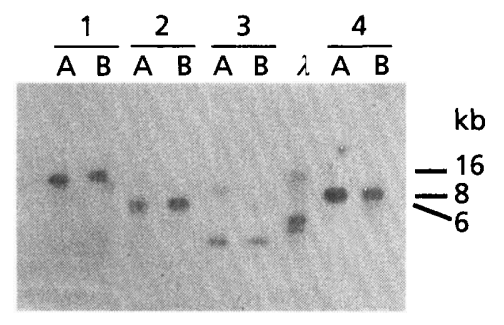

Fig. 4. Southern blot hybridization, with the probe specific for the aerobactin-uptake system, of pRK100 (lanes A) and pColVK30 (lanes B) digested with: 1, HindIII; 2, EcoRI/HindIII; 3, BamHI/HindIII; 4, EcoRI. Lane $\lambda$, labelled marker $\lambda$ DNA digested with EcoRI/HindIII.

conservation in pRK100 of the replicon RepFIB, a basic replicon found in large plasmids of the IncFI group (Gibbs et al., 1993) the aerobactin-uptake system and the two IS1 sequences (Figs 3, 4 and 5, respectively). Some but not all ColV plasmids also have the RepFIA homologous replicon downstream of the aerobactinuptake system. Since large plasmids are known to carry more than one replicon, first all EcoRI fragments of pRK100 were labelled and used to probe the Couturier bank of rep plasmids. The probe did not hybridize with the 917 bp EcoRI fragment of plasmid pUBL2154 harbouring RepFIA, demonstrating that pRK100 does not have this replicon. On the other hand the probe hybridized with fragments corresponding to RepFIC (the 967 bp EcoRI-HindIII fragment of pUBL2440), Rep9 (the 539 bp PstI fragment of pULB2422), RepFIIA copA (the $543 \mathrm{bp}$ PstI fragment of pUBL2401) and

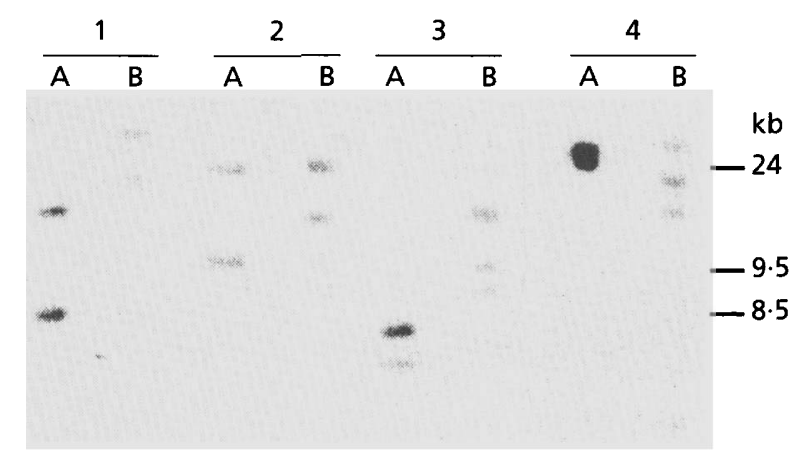

Fig. 5. Southern blot hybridization, with the IS1-specific probe, of pRK100 (lanes A) and pColV-K30 (lanes B) digested with: 1 HindIII; 2, ECoRI; 3, ECoRI/HindIII; 4,Sall.

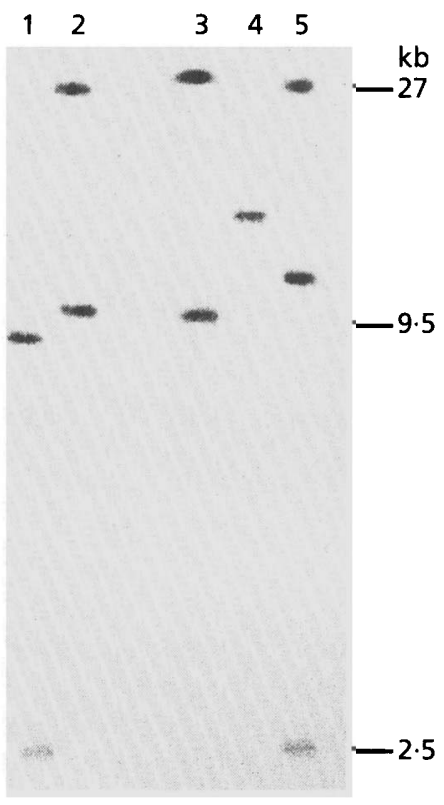

Fig. 6. Southern blot hybridization, with the RepFIC-specific probe, of pRK 100 digested with: lane 1, EcoRI/Sall; lane 2, EcoRI/HindIII; lane 3, EcoRI; lane 4, HindIII; lane 5, Sall.

RepFIIA $\operatorname{copB}$ (the 540 bp PstI fragment of pULB2402). All four are known to cross-hybridize. To determine their positions, the labelled RepFIC and Rep9 fragements were then used to probe restriction enzyme digests of pRK100. Both probes hybridized to the same two EcoRI, SalI and HindIII fragments, indicating that a replicon(s) of this family is present at two positions of pRK100 (Fig. 6).

\section{tra region and construction of the pRK100 map}

The pRK100 tra region was determined by hybridization of the labelled pED100 EcoRI fragments harbouring the tra operon of plasmid $\mathrm{F}$ and the labelled $8.3 \mathrm{~kb}$ EcoRI 


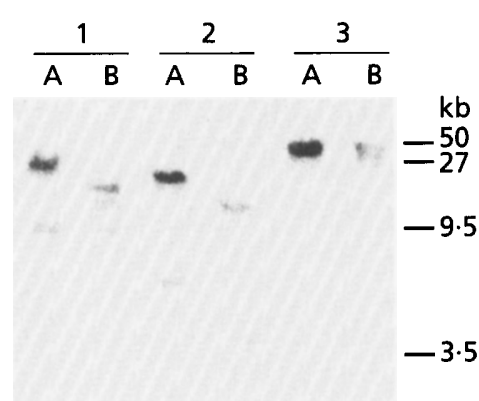

Fig. 7. Southern blot hybridization, with EcoRI fragments of the $F$ factor tra operon, of pRK100 (lanes A) and pColV-K30 (lanes B) digested with: 1, EcoRI; 2, EcoRI/Sall; 3, HindllI.

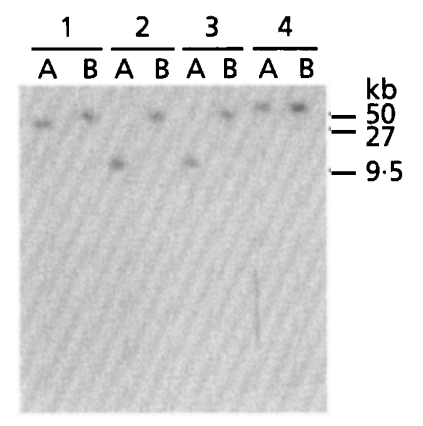

Fig. 8. Southern blot hybridization, with fragment $f 6$ of the $F$ factor tra operon specific probe, of pRK100 (lanes A) and pColV-K30 (lanes B) digested with: 1, Sall; 2, EcoRI/HindllI; 3, ECoRI; 4, HindIII.

fragment $\mathrm{f} 6$, to restriction fragments of pRK100 and pColVK30 (Figs 7 and 8, respectively). Comparison of the hybridization results for the tra region with the results obtained with the labelled $0.9 \mathrm{~kb}$ EcoRI-HindIII fragment of pFDH1 enabled us to deduce the position of the tra operon with regard to ColIa. Further comparison of the above results with the RepFIC and Rep9 hybridization patterns enabled us to deduce that a RepFIC replicon is downstream of ColIa. This was confirmed by single-stranded nucleotide sequencing with the forward sequencing primer of the pUX1 insert. Subsequently, by analysing the hybridization results obtained with probes specific for the aerobactin system, IS1 sequences, RepFIC and with the labelled $0.9 \mathrm{~kb}$ EcoRI-HindIII pFDH fragment, we were able to deduce the position of the tra operon on pRK100.

XboI cleaves pRK100 at only two sites, resulting in two fragments, of $26 \mathrm{~kb}$ and $120 \mathrm{~kb}$. One site was mapped in the ColV region, while the other was deduced from the fact that neither Tn5431 nor pFDH1 has a XhoI site and from fragment patterns of double restrictions.

On the basis of the above-mentioned results together with the fragment patterns of double restrictions, hybridization experiments using the three longest individually labelled EcoRI fragments $(27,20$ and $17 \mathrm{~kb}$ ),

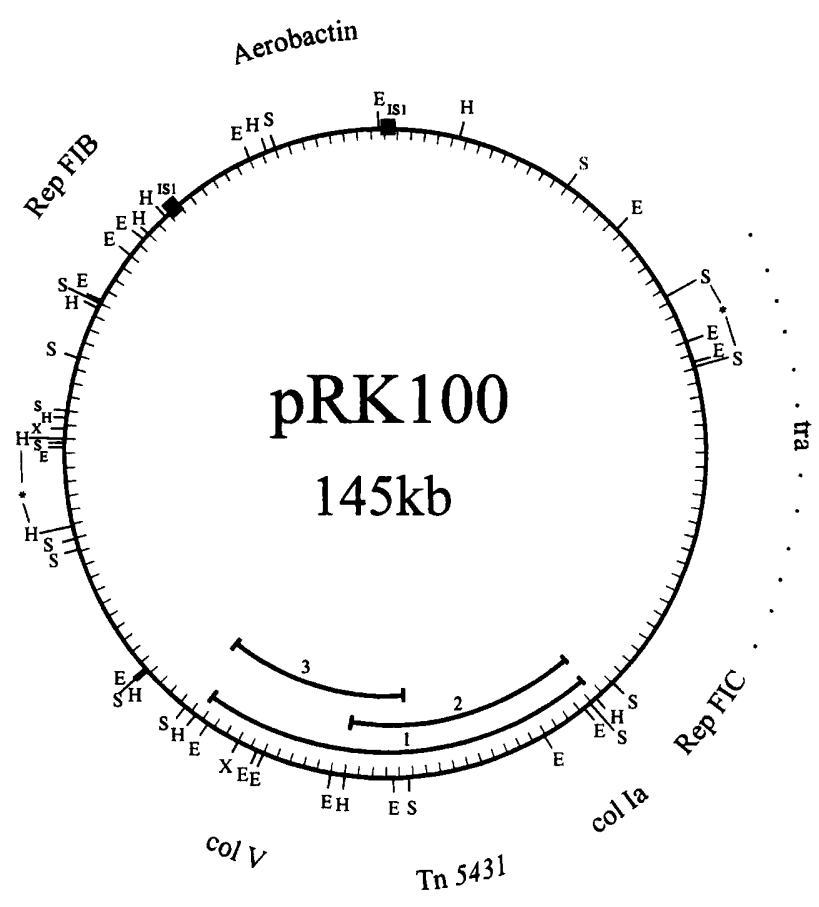

Fig. 9. Map of pRK100. On the inside border of the map are the boundaries of clones: 1, pFDH2; 2, pFDH1; 3, pFDHS1. The black boxes denote the two 151 insertion sequences. The asterisks in the bracketed area denote a region containing several small HindIII and Sall fragments.

Table 2. Survival in human serum of strains with and without pRK100

Percentage survival is expressed relative to that of bacteria incubated in buffer without serum. The experiment was repeated three times and the results presented are mean values.

\begin{tabular}{|lccc|}
\hline Strain & \multicolumn{3}{c|}{$\begin{array}{c}\text { Percentage survival in 1\%, 2\% } \\
\text { and 3\% serum: }\end{array}$} \\
\cline { 2 - 4 } & $\mathbf{3} \%$ & $\mathbf{2} \%$ & $\mathbf{3} \%$ \\
\hline C600 & $0 \cdot 4$ & $0 \cdot 03$ & 0 \\
C600(pRK100) & $1 \cdot 97$ & $0 \cdot 13$ & 0 \\
KS533 & 800 & 789 & 679 \\
KS533(pRK100) & 802 & 800 & 683 \\
\hline
\end{tabular}

and comparison of probe binding to pColV-K30 we were able to complete the restriction map (Fig. 9).

\section{Increased serum survival conferred by pRK100}

ColV plasmids have been shown to enhance serum resistance. TraT, the surface exclusion protein of the plasmid transfer system, and the iss (increased serum survival) locus, which is linked to the colicin $\mathrm{V}$ genes, have been implicated (Binns et al., 1979). Serum survival was tested for the original clinical strain KS533, strain C600 and C600 harbouring pRK100 in the presence of $1 \%, 2 \%$ and $3 \%$ human serum. The results (Table 2 ) 
Table 3. Plasmid transfer frequency to different species

Conjugal transfer frequencies are expressed as the proportion of transconjugants to recipients (means of three independent experiments). -, No transconjugants were isolated; - + , a small number of transconjugants were isolated only with plate mating; NT, not tested.

\begin{tabular}{|lccccc|}
\hline Plasmid & \multicolumn{5}{c|}{ Transfer frequency to: } \\
\cline { 2 - 6 } & E. coli & S. typhimurium & K. pneumoniae & E. cloacae & P. aeruginosa \\
\hline pRK100 & $2.4 \times 10^{-2}$ & - & $1.2 \times 10^{-6}$ & - & - \\
RSF2001* & $1.1 \times 10^{-2}$ & $3.7 \times 10^{-3}$ & $3.7 \times 10^{-7}$ & $-\dagger$ & NT \\
\hline
\end{tabular}

* RSF2001 is plasmid $\mathrm{F}$ with $\mathrm{Kn}^{\mathrm{R}}$.

show increased survival of C600 harbouring pRK100 in the presence of $1 \%$ and $2 \%$ serum (five- and fourfold, respectively) while both strains were killed in the presence of $3 \%$ serum. In contrast, both the clinical strain KS533 with plasmid pRK100 and strain KS533 without the plasmid exhibited growth at all serum concentrations tested. The K1 capsule thus offers much greater protection than any plasmid-encoded determinant.

\section{Stability and conjugal transfer to other Gram- negative bacteria}

Following 21 passages of pRK100 without antibiotic selection 1200 colonies were transferred to grids (LB plates) and tested for antibiotic resistances and colicinogenicity. All colonies retained the characteristics of the initial strain.

Stability of pRK100 was also studied by introduction of an incompatible plasmid, pED100, a $\mathrm{Cm}^{\mathrm{R}}$ derivative of F. A total of 152 colonies expressing the characteristics of both plasmids, resistances to $\mathrm{Ap}, \mathrm{Tc}, \mathrm{Cm}$ and colicinogenicity, were subsequently further subcultured by replica plating first onto an LB plate and then to an LB plate supplemented with $\mathrm{Cm}$. This procedure was repeated seven times, during which some colonies exhibited gradual loss of the $\mathrm{Cm}^{\mathrm{R}}$ character. None of the $\mathrm{Cm}^{\mathrm{R}}$ colonies exhibited loss of pRK100. Gel electrophoresis of the isolated plasmid DNA of strains which stably maintained colicinogenicity and antibiotic resistances of both plasmids $(\mathrm{Ap}, \mathrm{Tc}, \mathrm{Cm})$ showed the presence of both plasmids or only $F$ plasmid DNA, indicating integration of $\mathrm{pRK} 100$ into the chromosome. Only culturing strain KS533 in the presence of SDS yielded two colonies cured of plasmid pRK100.

To determine whether pRK100 can be transferred and maintained in other Gram-negative bacteria, conjugal transfer was attempted to S. typhimurium, K. pneumoniae, $P$. aeruginosa and Ent. cloacae. With plate mating only a small number of $K$. pneumoniae tranconjugants harbouring pRK100 were isolated. Liquid matings were also carried out and the transfer frequencies of pRK100 and RSF2001 were compared (Table 3). pRK100 and RSF2001 were both transferred at low frequency to K. pneumoniae. On the other hand while the transfer frequency of RSF2001 to $S$. typhimurium was comparable with that to $E$. coli, transfer of $\mathrm{pRK} 100$ to S. typhimurium was never detected. Transfer of RSF2001 to Ent. cloacae was detected only with plate mating.

\section{Chromosomal virulence-associated genes of strain KS533}

Hybridization experiments demonstrated the presence of nucleotide sequences specific for type I, P and S fimbriae. PCR was carried out with primers specific for CNF1 but amplification of the corresponding fragment was not detected. KS533 does not produce haemolysin as determined by growth on blood agar plates.

\section{DISCUSSION}

Using hybridization and nucleotide sequencing a map of plasmid pRK100 and its characteristics was constructed. Transposon Tn5431 has transposed into the direct vicinity of the Colla immunity and structural genes. Prior to transposition the ColV and Colla genes were thus linked. The ColV operon has so far been determined only on plasmids of the IncF1 incompatibility group, which share replicon RepFIB, colicin V genes and - in most of the plasmids examined - the aerobactin-uptake system. On the other hand, examination of Collaharbouring plasmids of the E. coli Reference Collection (ECOR) showed that ColIa is present on large plasmids with little homology. It was therefore suggested that the Colla operon or some larger fragment has been transferred between distinct plasmid lineages (Riley \& Gordon, 1992). On pRK100 the conserved Colla sequences are on one side separated from ColV by approximately $2.6 \mathrm{~kb}$ and on the other side, upstream of the conserved RepFIC sequences, by approximately $1.5 \mathrm{~kb}$. Together with the Colla sequences this is roughly the size of the fragment homologous to different Collacarrying plasmids (Riley \& Gordon, 1992). Sequences involved in Colla transfer could be present in the vicinity of the ColIa and ColV determinants of pRK100.

Using specific probes we demonstrated that pRK100 harbours RepFIB and RepFIC. It is not yet known 

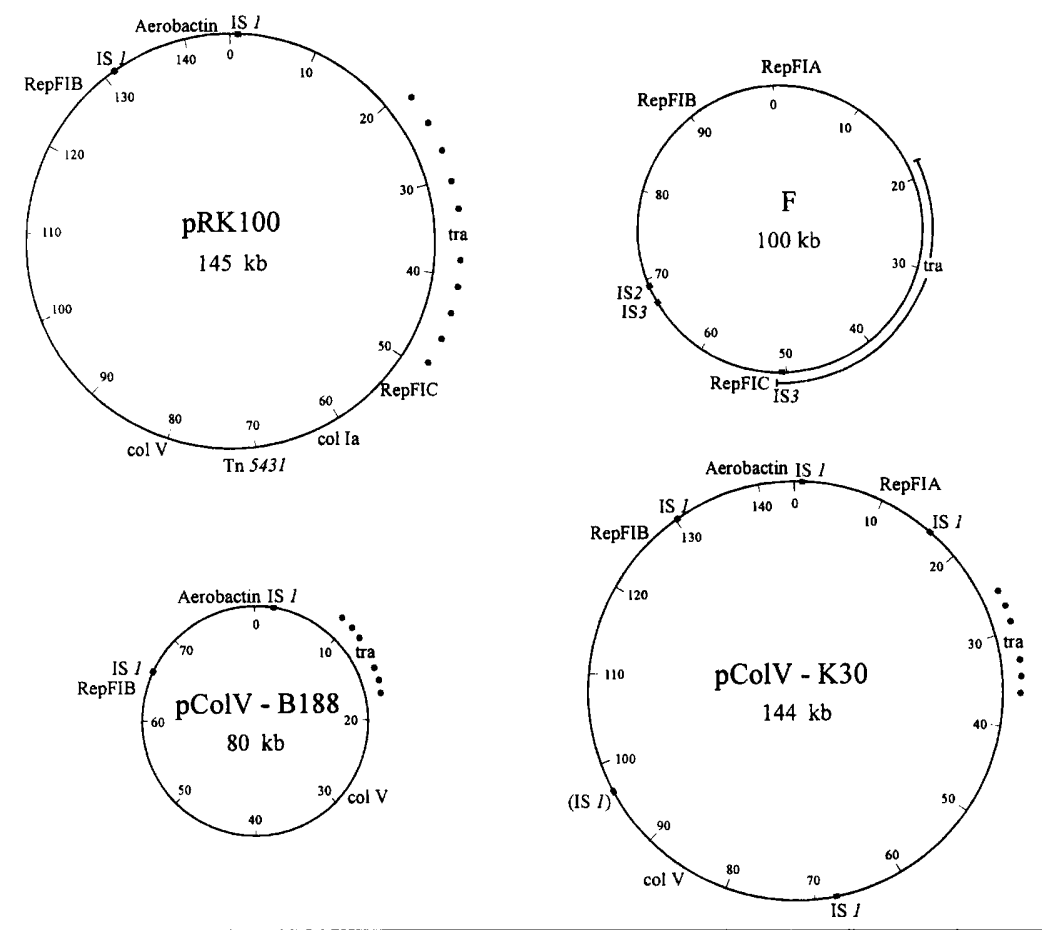

\begin{abstract}
Fig. 10. Comparison of the map of pRK100 with those of plasmid $F$ (adapted from Neville et al., 1996) and the ColV plasmids pColV-K30 and pColV-B188 (Waters et al., 1989). The location of insertion sequences (IS) is shown by black boxes. The IS1 copy which is believed to be partial is labelled in parentheses. Dotted lines indicate that the location of the tra region is approximate, within the limits of available restriction enzyme sites. Numbers within the maps indicate kilobase coordinates.
\end{abstract}

whether pRK100 carries a complete and functional RepFIC replicon. However, when pRK100 was challenged with an incompatible plasmid, integration of pRK100 into the chromosome or the coexistence of both plasmids was observed, indicating that pRK100 has two functional replication regions. Further, on the basis of binding of probes specific for RepFIC and the tra region we demonstrated that in pRK100 the tra region is, as in plasmid F, linked to the RepFIC replication region. Other ColV plasmids, including pColV-K30, also harbour RepFIC sequences; however, their locations have not been determined (Bergquist et al., 1986).

Colicinogenicity and conjugal transfer contribute to plasmid stability in bacterial populations. Cells which have lost the plasmid are no longer immune and can be killed by plasmid-harbouring cells. Further, cells which have lost the plasmid can act as recipients in conjugal transfer. However, our experiments demonstrated pronounced in vitro stability of pRK100. Colonies cured of the plasmid were isolated only by SDS treatment. Further, the spontaneous loss of pRK100 upon subculturing and storage was never observed. Introduction of an incompatible plasmid could result in integration of pRK100 into the chromosome, probably by recombination between chromosomal and plasmid insertion sequences. Integration of plasmids is known to reduce the expression of plasmid-encoded factors due to differential supercoiling of the integrated plasmid DNA (Ott, 1993). It might also be viewed as a means by which selfish DNA avoids elimination in conditions detrimental to maintenance. The influence of environmental signals in the regulation of integration will be investigated. On plasmids such as pRK100, the maintenance of genes is stable while having, with regard to chromo- somal genes, the additional advantage of being able to disseminate through a population by conjugation.

As well as plasmid-encoded determinants, strain KS533 also has chromosomal virulence determinants important for eliciting extraintestinal infections. The $\mathrm{K} 1$ capsule is poorly immunogenic and is responsible for immunotolerance by the host. Type P fimbriae mediate the initial binding of uropathogenic $E$. coli to its host receptor.

Fifteen per cent of the ECOR strains possess F-related plasmids (Boyd et al., 1996). The Salmonella Reference Collection A (SARA) also has approximately the same percentage of F-like plasmids and it has been inferred that $\mathrm{F}$ plasmid transfer is an important mechanism of interspecies recombination (Boyd \& Hartl, 1997). Salmonella IncF1 R plasmids are known to carry the IS1bound aerobactin-uptake system (Colonna et al., 1985) and some Salmonella isolates harbour colicin plasmids (Ayala et al., 1994). Besides, some E. coli virulence factors might have originated in some other species (Mühldorfer \& Hacker, 1994). On the other hand, ColV plasmids have been determined only in E. coli even though the replication and transfer regions of plasmid $F$ and ColV plasmids are homologous and exhibit a high degree of sequence conservation (Gibbs et al., 1993). It could be that for some reason DNA restriction and modification is more efficient in reducing or eliminating recombinants carrying ColV plasmid than $\mathrm{F}$ plasmid recombinants. In our plasmid-transfer experiments only $K$. pneumoniae transconjugants harbouring pRK100 were isolated. By comparing the host range of plasmids RSF2001 and pRK100 we see that the latter cannot be transferred to S. typhimurium or Ent. cloacae even though both plasmids are transferred to another E. coli 
strain with approximately the same frequencies. The absence of the RepFIA replication region in pRK100 could also be responsible for the plasmid's limited host range when compared with plasmid F. Plasmid host range is important particularly for transferable plasmids. Conjugal transfer of plasmid-encoded virulence properties to another strain or species could provide quantum leaps toward virulence. The role of RepFIA in plasmid host range will be investigated. As environmental stimuli regulate gene expression and gene transfer (Mel \& Mekalanos, 1996), experiments will be carried out to determine the in vivo stability and transfer of pRK100.

The maps of plasmids pRK100, $\mathrm{F}$ and two other known ColV plasmids - pColV-K30 and pColV-B188 - are presented in Fig. 10. The tra regions of the ColV plasmids are approximate, but with regard to the well-studied tra region of plasmid $F$ should span about $30 \mathrm{~kb}$. The aerobactin iron-uptake system which is encoded by most of the ColV plasmids is found on plasmids and chromosomes among E. coli, Shigella and Salmonella species. The ubiquity of the system can be explained by IS1-mediated genetic mobility via recombination or probably less frequently by transposition (Waters \& Crosa, 1991). By comparing the maps of the ColV plasmids and plasmid $\mathrm{F}$ it can be inferred that acquisition of IS1 sequences could have been important in the evolution of ColV plasmids. It can be envisaged that the aerobactin system integrated via IS1-mediated recombination into the region between the RepFIB and RepFIA replicons of an ancestral F-like plasmid. Recombination between two copies of IS1 could result in deletion of the RepFIA replication region.

It is evident that pRK100 evolved in several steps. First a segment encoding the Colla operon was transferred from one plasmid to a ColV plasmid, then transposon Tn5431 transposed into sequences in the direct vicinity of the Colla operon. By comparing pRK100 with plasmids F and pColV-K30 (Fig. 10) we see that deletion of the RepFIA replication region could have occurred by IS1-mediated recombination. However, other rearrangements must have taken place, as sequences homologous to the RepFIC probe were also detected in the region between RepFIB and the ColV genes. A pronounced clustering of virulence-related properties is also evident in pRK100 when compared with other ColV plasmids. An insertion hotspot could be present in the Colla region and/or there could be a constraint on insertions in the region between the RepFIB and colicin V genes. The presence of transposable antibiotic resistances on a ColV plasmid is a reflection of the widespread use of antibiotics. The aerobactin iron-uptake system, the tra region, the ColV and Colla genes, and the transposable antibiotic resistance genes together with the replication regions could be considered a stable transferable pathogenicity island.

Plasmid pRK100 and the constructed map will also enable further studies of sequences involved in transfer of the Colla genes, the role of certain replicons in plasmid host range and gene clustering on large plasmids encoding virulence properties.

\section{ACKNOWLEDGEMENTS}

The authors thank J.B. Neilands for providing plasmid pABN1, R. Kolter for pHK11, V. De Lorenzo for pED100, M. Chandler for pTC72\#24, J. Hacker for pPKL4, pRHU845, pANN801-13, M. Couturier for the plasmids of the Rep bank, A. Pugsley for the Pugsley collection of strains and P. R. Lehrbach for pColV-K30. This research was supported by Grant J1-574 of the Ministry of Science and Technology, Slovenia.

\section{REFERENCES}

Ayala, F. J., Krane, D. E. \& Hartl, D. L. (1994). Genetic variation in IncI1-ColIb plasmids. J Mol Evol 39, 129-133.

Bergquist, P. L., Saadi, S. \& Maas, W. K. (1986). Distribution of basic replicons having homology with RepF1A, RepF1B, and RepF1C among IncF group plasmids. Plasmid 15, 19-34.

Binns, M. M., Davies, D. L. \& Hardy, K. G. (1979). Cloned fragments of the plasmid ColV,I-K94 specifying virulence and serum resistance. Nature 279, 778-781.

Blum, G., Vincenzo, F., Caprioli, A. \& Hacker, J. (1995). Gene clusters encoding the cytotoxic necrotizing factor type 1, Prsfimbriae and $\alpha$-hemolysin form the pathogenicity island II of the uropathogenic Escherichia coli strain J96. FEMS Microbiol Lett 126, 189-196.

Boyd, F. E., Hill, C. W., Rich, S. M. \& Hartl, D. L. (1996). Mosaic structure of plasmids from natural populations of Escherichia coli. Genetics 143, 1091-1100.

Boyd, F. E. \& Hartl, D. L. (1997). Recent horizontal transmission of plasmids between natural populations of Esherichia coli and Salmonella enterica. J Bacteriol 179, 1622-1627.

Braun, V., Pilsl, H. \& Groß, P. (1994). Colicins: structures, mode of action, transfer through membranes, and evolution. Arch Microbiol 161, 199-206.

Collee, J. G. \& Miles, R. S. (1989). Tests for identification of bacteria. In Practical Medical Microbiology, pp. 141-160. Edited by J. G. Collee, J. P. Duguid, A. G. Fraser \& B. P. Marmion. Edinburgh: Churchill Livingstone.

Colonna, B., Nicolette, M., Visca, P., Casalino, M., Valenti, P. \& Maimone, F. (1985). Composite IS1 elements encoding hydrozamate-mediated uptake in FIme plasmids from epidemic Salmonella spp. J Bacteriol 162, 307-316.

Couturier, M., Bex, F., Bergquist, P. L. \& Maas, W. K. (1988). Identification and classification of bacterial plasmids. Microbiol Rev 52, 375-395.

De Lorenzo, V., Bindereif, A., Paw, B. H. \& Neilands, J. B. (1986). Aerobactin biosynthesis and transport genes of plasmid ColV$\mathrm{K} 30$ in Escherichia coli K-12. J Bacteriol 165, 570-578.

Gibbs, M. D., Spiers, A. J. \& Bergquist, P. L. (1993). RepFIB: a basic replicon of large plasmids. Plasmid 29, 165-179.

Gilson, L., Mahatny, H. K. \& Kolter, R. (1987). Four plasmid genes are required for colicin $\mathrm{V}$ synthesis, export, and immunity. $J$ Bacteriol 169, 2466-2470.

Gratia, A. (1925). Sur un remarquable example d'antagisme entre deux souches de collibacille. C R Soc Biol 93, 1041-1042.

Hardy, K. G. (1987). Plasmids: a Practical Approach, pp. 105-161. Oxford: IRL Press. 
Heffron, F., Bedinger, P., Champoux, J. J. \& Falkow, S. (1977). Deletions affecting the transposition of an antibiotic resistance gene. Proc Natl Acad Sci 74, 702-706.

Lehrbach, P. R. \& Broda, P. (1984). Molecular comparisons of plasmids isolated from colicinogenic strains of Escherichia coli.J Gen Microbiol 130, 401-410.

Mel, S. F. \& Mekalanos, J. J. (1996). Modulation of horizontal gene transfer in pathogenic bacteria by in vivo signals. Cell 87 , 795-789.

Moll, A., Manning, P. A. \& Timmis, K. N. (1980). Plasmiddetermined resistance to serum bactericidal activity: a major outer membrane protein, the traT gene product, is responsible for plasmid-specified serum resistance in Escherichia coli. Infect Immun 28, 359-367.

Mühldorfer, I. \& Hacker, J. (1994). Genetic aspects of Escherichia coli virulence. Microb Pathog 16, 171-181.

Neville, F., Ippen-Ihler, K. \& Skurray, R. A. (1996). Structure and function of the $\mathrm{F}$ factor and mechanism of conjugation. In Escherichia coli and Salmonella: Cellular and Molecular Biology, 2nd edn, pp. 2378. Edited by F. C. Neidhardt and others. Washington, DC: American Society for Microbiology.

Ørskov, I. \& Ørskov, F. (1992). Escherichia coli serotyping and disease in man and animals. Can J Microbiol 38, 699-704.

Ott, M. (1993). Dynamics of the bacterial genome: deletions and integrations as mechanisms of bacterial virulence modulation. Zentralbl Bakteriol 278, 457-468.

Ott, M., Bender, L., Blum, G., Schmittroth, M., Achtman, M., Tschäpe, H. \& Hacker, J. (1991). Virulence patterns and long-range genetic mapping of extraintestinal Escherichia coli $\mathrm{K} 1, \mathrm{~K} 5$, and K100 isolates: use of pulse-field gel electrophoresis. Infect Immun 59, 2664-2672.

Pugsley, A. P. (1985). Escherichia coli K12 strains for use in the identification and characterization of colicins. J Gen Microbiol 131, 369-376.

Riley, M. A. \& Gordon, D. M. (1992). A survey of Col plasmids in natural isolates of Escherichia coli and an investigation into the stability of Col-plasmid lineages. J Gen Microbiol 138, 1345-1352.

Sambrook, J., Fritsch, E. F., \& Maniatis, T. (1989). Molecular Cloning: a Laboratory Manual. Cold Spring Harbor, NY: Cold Spring Harbor Laboratory.

Waters, V. L. \& Crosa, J.H. (1986). DNA environment of the aerobactin iron uptake system genes in prototypic ColV plasmids. $J$ Bacteriol 167, 647-654.

Waters, V. L. \& Crosa, J. H. (1991). Colicin V virulence plasmid. Microbiol Rev 55, 437-450.

Waters, V. L., Perez-Casals, J. F. \& Crosa, J. H. (1989). ColV plasmids pColV-B188 and pColV-K30: genetic maps according to restriction enzyme sites and landmark phenotypic characteristics. Plasmid 22, 224-248.

Willets, N. \& Johnson, D. (1981). pED100, a conjugative F plasmid derivative without insertion sequences. Mol Gen Genet 182, 520-522.

Wooley, R. E., Nolan, L. K., Brown, J., Gibbs, P. S. \& Bounous, D. I. (1994). Phenotypic expression of recombinant plasmids pKT107 and pHK11 in an avirulent avian Escherichia coli. Avian Dis 38, 127-134.

Yanisch-Perron, C., Vieira, J. \& Messing, J. (1985). Improved M13 phage cloning vectors and host strains: nucleotide sequences of the M13mp18 and pUC19 vectors. Gene 33, 103-109.

Žgur-Bertok, D. \& Grabnar, M. (1990). Aerobactin uptake system, ColV production and drug resistance encoded by a plasmid from a urinary tract infection Escherichia coli strain of human origin. Can J Microbiol 36, 297-299.

Žgur-Bertok, D., Ambrožič, J., Podlesek, Z. \& Grabnar, M. (1994). Tn5431, a new transposable element composed of Tn1721- and Tn3-like genes. Plasmid 32, 95-99.

Žgur-Bertok, D., Ambrožič, J. \& Grabnar, M. (1996). Tn5431 arose by transposition of $\operatorname{Tn} 3$ into Tn1721. Can J Microbiol 42, $1274-1276$.

Received 2 July 1997; revised 29 September 1997; accepted 6 October 1997. 